\section{Steroid induced osteoporosis}

EDITOR,- The comment and discussion in the Brompton Grand Round on corticosteroid induced osteoporosis in severe menstrual asthma might lead to some confusion. ${ }^{1}$ The statement that "steroid osteoporosis is always preventable and treatable" is misleading. We are convinced that the use of corticosteroids is an important cause of secondary osteoporosis, which is not easy to prevent or to treat. ${ }^{2}$ The fracture rate of asthmatic patients treated with steroids can be as much as $40 \%$.

We cannot agree with the remark that "with high dose corticosteroids, virtually all the excess bone mineral loss is sustained in the first year. Thereafter, the loss of bone mineral density does not differ significantly from that in controls." This conclusion is based mainly on a study in four asthmatic patients in whom bone loss during treatment with a mean dose of $15 \mathrm{mg}$ prednisone/ day resulted in rapid bone loss within the first year; only a small further decrease in bone mass in the following three years was found. ${ }^{+}$In other studies, bone loss in patients using corticosteroids was gradual $^{5}$ or related to the cumulative dose of corticosteroids. ${ }^{\circ}$ In a study on the effect of APD on corticosteroid induced osteoporosis ${ }^{7}$ bone loss in the placebo group was $18 \%$ in the first year and an additional $10 \%$ (of the initial value) in the second year of treatment. Therefore corticosteroids should be prescribed in the lowest possible dose and as briefly as possible. The statement that bone loss occurs only in the first year may lead to the use of steroids over longer periods in subsequent years.

With regard to the mechanisms involved: long term corticosteroid therapy decreases the intestinal absorption of calcium and increases the renal excretion of calcium. This leads to hypocalcaemia, which stimulates secretion of parathyroid hormone, resulting in increased bone resorption. Furthermore, bone formation is decreased during corticosteroid therapy. The combination of increased bone resorption and decreased bone formation leads to bone loss. To counteract the hypocalcaemia we advise calcium supplementation in patients using corticosteroids ${ }^{8}$ and supplementation of vitamin $\mathrm{D}$ only if there is a vitamin $\mathrm{D}$ deficiency. There have been no studies on the prevention of steroid induced osteoporosis proving a reduction of fracture rate, but some studies have shown a positive effect of bifosfonates and calcitonin on bone mass. ${ }^{79}$

The prevention and treatment of steroid induced osteoporosis is still an enormous problem that should not be underestimated.

WF LEMS

Department of Rheumatology,

J W J BIJLSMA

University Hospital Utrecht, FO2.223,

PO Box 85500,3508 GA Utrecht,

Netherlands

1 Wells AU. Corticosteroid induced osteoporosis in severe menstrual asthma. BMf 1992;305:413-5. (15 August.)

2 Lukert BP, Raisz LG. Glucocorticoid-induced osteoporosis: pathogenesis and management. Ann Intern Med 1990;112 pathoge

3 Adinoff $\mathrm{AD}$, Hollister JR. Steroid-induced fractures and bone loss in patients with asthma. $N$ Engl F Med 1983;309:265-8.

4 Gennari C, Civitelli R. Glucocorticoid-induced osteoporosis. Clinics in Rheumatic Diseases 1986;12:637-54

5 Ruegsegger P, Medici TC, Anliker M. Corticosteroid-induced bone loss. A longitudinal study in patients with bronchia asthma using quantitative computed tomography. Eur $\mathcal{f} \mathrm{Clin}$ Pharmacol 1983;25:615-20.

6 Dyckman TR, Gluck OS, Murphy WA, Hahn TJ, Hahn BH. Evaluation of factors associated with glucocorticoid-induce osteopenia in patients with rheumatic diseases. Arhritis Rheum 1985;28:361-8.

7 Reid IR, King AR, Alexander CJ, Ibbertson HK. Prevention of steroid-induced osteoporosis with (3-amino-1-hydroxypropylidene)-1,1-biphosphonate (APD). Lancet 1988;i:143-6.

8 Bijlsma JWJ, Raymakers JA, Mosch C, et al. Effect of oral calcium and vitamin $\mathrm{D}$ on glucocorticoid-induced osteopenia. Ciin Exp Rheumatol 1988;6:113-9.

9 Ringe JD, Welzel D, Schmid K. Therapy of corticoid-induced osteoporosis with salmon calcitonin. Osteoporosis 1987;1074-6.
EDITOR,- - The case presented at the Brompton Grand Round by A U Wells reminds of the postulated immunosuppressive effects of progesterone.' This young woman had asthmatic symptoms that worsened before and during menstrual periods. The report fails to discuss the possibility that treatment of the patient's disorder with high doses of the synthetic progestin medroxyprogesterone acetate may have contributed to the severe osteoporotic complications manifesting during the follow up.

Medroxyprogesterone acetate is a potent synthetic progestin but it also acts like a glucocorticoid, binding with a high affinity to the human glucocorticoid receptors." When compared with a reference compound, dexamethasone (relative receptor binding affinity defined as $100 \%$ ), medroxyprogesterone acetate has a binding affinity of $46 \%$, which clearly exceeds the binding affinity of cortisol $(25 \%)$. Moreover, medroxyprogesterone acetate induces glucocorticoid-like effects on the functions of human mononuclear leucocytes. These include an inhibition of the proliferative responses of these cells to the $T$ cell mitogens concanavalin $\mathrm{A}$ and phytohaemagglutinin. ${ }^{2}$ These in vitro data are substantiated by experience in vivo.

Giving $100-150 \mathrm{mg}$ of medroxyprogesterone acetate daily has been reported to suppress the function of the pituitary-adrenal axis in humans. Weekly doses of 400-1200 mg reduce the plasma cortisol concentrations by an average of $75 \%$ and in some patients to an unmeasurable level; it is of note that no signs of adrenal insufficiency appear under these conditions.' Furthermore, very high doses (up to 400-1000 mg daily) of medroxyprogesterone acetate may result in Cushing's syndrome, with symptoms of glucocorticoid withdrawal and subsequent regression of the cushingoid features after discontinuation of the drug. ${ }^{5}$

The patient described received $1200 \mathrm{mg}$ medroxyprogesterone acetate weekly for almost a year. ' It cannot be stated with certainty to what extent progestin treatment ultimately contributed to the appearance of the skeletal complications, including aseptic bone necrosis, osteoporosis, and fractures, since the patient had received ora prednisone and inhaled beclomethasone for an even longer period. However, considering the timing of the manifestations of these complications in relation to treatment with medroxyprogesterone acetate - and the facts that the patient had received doses of medroxyprogesterone acetate 10 times higher than those of prednisone ${ }^{1}$ and that prednisolone (the biologically active form of prednisone) and medroxyprogesterone acetate are approximately equipotent corticoids at the cellular level ${ }^{27}$ - there is a strong reason to believe that medroxyprogesterone acetate was involved.

In summary, a number of clinical and experimental observations suggest that side effects attributable to the inherent glucocorticoid-like activity of certain progestins derived from pregnane in wide clinical use may be expected when these steroids are used in pharmacological doses. Occasionally it may perhaps be more prudent to prescribe progestins of the 19. nortestosterone type which, although possessing slight androgenic activity, seem to be devoid of any glucocorticoid-like characteristics. ${ }^{12}$

Second Department of Medicine, KIMMO KONTULA

University of Helsinki,

00290 Helsinki,

Finland

1 Wells AU. Corticosteroid induced osteoporosis in severe menstrual asthma $B M 7$ 1992;305:413-5. (15 August.)

2 Kontula K, Paavonen T, Luukkainen T, Andersson LC. Bindin of progestins to the glucocorticoid receptor. Correlation to of progestins to the glucocorticoid receptor. Correlation to
their glucocorticoid-like effects on in vitro functions of human their glucocorticoid-like effects on in vitro functions of human
mononuclear leukocytes. Biochem Pharmacol 1983;32:1511-8.

3 Mathews JH, Abrams CAL, Morishima A. Pituitary-adrenal function in ten patients receiving medroxyprogesterone acetate for true precocious puberty. 7 Clin Endocrinol Metab 1970;30: 653-8.
4 Hellman L, Yoshida K, Zumoff B, Levin J, Kream J, Fukushima DK. The effect of medroxyprogesterone acetate on the pituitary-adrenal axis. F Clin Endocrinol Metab 1976;42 912-7.

5 Siminoski K, Goss P, Drucker DJ. The Cushing syndrome induced by medroxyprogesterone acetate. Am Intern Med 1989;111:758-60.

6 Donckier JE, Michel LA, Buysschaert M. Cushing syndrome and medroxyprogesterone acetate. Lancet 1990;335:1094.

7 Kontula K, Myllylä G, Andersson LC. Glucocorticoid receptors in human polymorphonuclear and mononuclear leukocytes. Concentrations and binding characteristics. Scand $\mathcal{f}$ Haematol 1981;27:145-51.

Authors' Reply,-W F Lems and J W J Bijlsma point to our comment concerning the loss of bone mineral within the first year and refer to work that suggests that bone loss with steroid therapy may be more gradual. However, the references they quote do not support their point. The study by Ruegsegger et al was a one year trial comparing daily with alternate day steroid therapy and presented no data on possible rates of change of bone mineral loss. ' The study by Reid et al was a one year trial, the results of which do not bear any resemblance to those quoted by Lems and Bijlsma.?

Kimmo Kontula points to the potential glucocorticoid effects of medroxyprogesterone acetate and suggests that the effects of higher doses to the patient could have been induced through the stimulation of glucocorticoid receptors. We were aware of the potential glucocorticoid effects of medroxyprogesterone acetate in inducing a reversible suppression of the pituitary-adrenal axis. ${ }^{3}$ However, we believe that it is unlikely that medroxyprogesterone acetate was acting through its potential glucocorticoid properties because the patient's asthma was totally uncontrolled despite her receiving high doses of prednisolone during the year preceding treatment with medroxyprogesterone acetate. We believe that the beneficial actions of medroxyprogesterone acetate relate to its progesterone effects

The patient had received high dose corticosteroid therapy for 12 years before the start of medroxyprogesterone acetate therapy and there was already evidence of reduced bone density at that time. Whether treatment with medroxyprogesterone acetate contributed to further bone loss and osteoporotic complications is not possible to ascertain. Although the in vivo study of Kontula et al shows that medroxyprogesterone acetate binds to the glucocorticoid receptor on human monocytes, treatment with high doses of medroxyprogesterone acetate does not result in Cushing's syndrome. Thus there seems to be some discrepancy between the in vitro and the in vivo effects of medroxyprogesterone acetate. In addition, in this study, there is no mention of osteoporotic complications even though some of these patients were treated with $1200 \mathrm{mg}$ of medroxyprogesterone acetate for up to 86 weeks. Although we question whether the potent effects of medroxyprogesterone acetate on human leucocytes in vitro ${ }^{3}$ can be extrapolated to predict the likely effects of the drug in patients, in vivo studies of medroxyprogesterone acetate on bone metabolism are needed.

National Heart and Lung Institute,

London SW3 $6 \mathrm{LY}$

Royal National Orthopaedic Hospital,

T STAMP

Stanmore,

Middlesex

1 Ruegsegger P, Medici TC, Anliker M. Corticosteroid-induced bone loss. A longitudinal study in patients with bronchial asthma using quantitative computed tomography. Eur $\mathrm{f}$ Clin Pharmacol 1983;25:615-20.

2 Reid IR, King AR, Alexander CJ, Ibbertson HK. Prevention of steroid-induced osteoporosis with (3-amino-1-hydroxypropylidene)-1, 1-bisphosphonate (APD). Lancet 1988;i:143-6.

3 Hellman L, Yoshida K, Zumoff B, Levin J, Kream J, Fukushima DK. The effect of medroxyprogesterone acetate on the DK. The effect of medroxyprogesterone acetate on the
pituitary-adrenal axis. F Clin Endocrinol Metab 1975;42:912-7. 4 Kontula K, Paavonen T, Luukkainen T, Andersson LC. Binding of progestins to the glucocorticoid receptor. Biochem Pharmacol of progestins to the
$1983 ; 32: 1511-8$. 